\title{
A clinicopathological study of correlation of clinical, sonological and histopathological findings following hysterectomy for abnormal uterine bleeding based on PALM-COEIN Classification
}

\author{
Prema $N^{1}$, Sudhakaran $R^{2}$, Divya. B. ${ }^{3}$, Meerabai $V^{4}$, Maharani ${ }^{5}$ \\ ${ }^{1}$ Dr. Prema N, Assistant Professor, Department of Obstetrics and Gynaecology, ${ }^{2}$ Dr. Sudhakaran R, Assistant Professor, \\ Department of Anaesthesia, ${ }^{3}$ Dr. Divya. B.V., Assistant Professor, Department of Community Medicine, ${ }^{4}$ Dr. Meerabai V., \\ Professor, Department of Obstetrics and Gynaecology, ${ }^{5}$ Dr. Maharani, Professor, Department of Obstetrics and Gynaecology; \\ all authors are affiliated with Karpagam Faculty of Medical Sciences and Research, Coimbatore, Tamilnadu, India.
}

Address for Correspondence: Dr. Prema. N, 105, A-block, Staff Quarters, Karpagam Faculty of Medical Sciences And Research, Othakkalmandapam, Coimbatore, Tamilnadu, India. Email: drnprema@gmail.com

\begin{abstract}
Background: To identify the proportion of different causes of Abnormal Uterine Bleeding in women undergoing hysterectomy according to the PALM COEIN classification proposed by FIGO. Methods: Collection of data was done from the medical records of women who underwent hysterectomy for Abnormal Uterine Bleeding in the study period from January 2015 to June 2016. Women who underwent planned abdominal hysterectomy and laparoscopy assisted vaginal hysterectomy for Abnormal Uterine Bleeding were included in the study. The clinical, sonological and histopathologic findings were analyzed so as to identify the proportion of different causes of Abnormal Uterine Bleeding in women undergoing hysterectomy. Causes of Abnormal Uterine Bleeding were categorized by calculating the percentage according to the PALMCOEIN classification. Results: A total of 214 women with Abnormal Uterine Bleeding underwent hysterectomy out of which 148 had planned abdominal hysterectomy and 66 had planned laparoscopy assisted vaginal hysterectomy, in the study period. AUB-L was the commonest histopathology (38.3\%cases) followed by AUB-O (22\%cases) and about $21.5 \%$ had adenomyosis. Heavy menstrual bleeding was the commonest presenting symptom ( $24.3 \%$ cases) while $40 \%$ and $36 \%$ had irregular and frequent menstrual bleeding respectively. Conclusion: FIGO has proposed this new standardized terminology to provide uniform conduct of research as data could be compared both nationally and internationally without any confusion and classify the causes of Abnormal Uterine Bleeding according to PALMCOEIN and identify the relative proportions of each cause. This will help in further research for comparative and epidemiological studies in various populations. More research is needed to identify the riskfactors for leiomyoma in our region as it more prevalent here.
\end{abstract}

Keyword: Abdominal hysterectomy, Abnormal Uterine Bleeding (AUB), International Federation of Gynecology and Obstetrics (FIGO), PALM-COEIN Classification, Laparoscopy Assisted Vaginal Hysterectomy, Histopathology.

\section{Introduction}

Abnormal uterine bleeding (AUB) is defined as any change in the frequency of menstruation, duration of flow or amount of blood loss $[1,2,3]$. One of the commonest symptoms among women of all age groups is AUB for which there are several causes. AUB is responsible for around 20 to $30 \%$ visits to outpatient department in reproductive age group and $69 \%$ in peri or postmenopausal age group. Accurate analysis of the etiology of AUB in non gravid women of reproductive age was not possible before International Federation of Gynaecology and Obstetrics (FIGO) updated the

Manuscript received: $10^{\text {th }}$ December 2016

Reviewed: $17^{\text {th }}$ December 2016

Author Corrected: $26^{\text {th }}$ December 2016

Accepted for Publication: $31^{\text {st }}$ December 2016

Obsgyne Review: Journal of Obstetrics and Gynecology terminology, definitions and classification of AUB. The PALM-COEIN Classification System $[1,2]$ is the new classification for causes of AUB and is composed of PALM: Visually objective structural criteria; COEI: unrelated to structural anomalies; N:entities Not yet classified.

The classification system consists of nine basic categories arranged according to the acronym PALM-COEIN: Polyp, Adenomyosis, Leiomyoma, Malignancy and hyperplasia, Coagulopathy, Ovulatory Disorders, Endometrium, Iatrogenic, and Not Classified. No studies have been conducted with the new classification system in our area.

Available online at: www.medresearch.in $64 \mid \mathrm{P}$ a g e 
Our objective is to conduct a clinicopathological study of correlation of clinical, sonological and histopathological findings following hysterectomy for AUB based on PALM-COEIN classification as hysterectomy still remains the widely accepted and practiced treatment of choice for AUB in spite of the availability of a number of minimally invasive promising surgical alternatives for hysterectomy like endometrial ablation, thermal balloon therapy and uterine artery embolisation as restricted availability and cost factor limit them from being used widely.

\section{Materials and Methods}

Study setting: Department of obstetrics and gynaecology, Karpagam Faculty of Medical Sciences and Research.

Study design: Retrospective, cross sectional, observational study.

Study population: Non gravid women who had undergone hysterectomy for AUB during the study period Study period: From January 2015 to June 2016.

Study tool: Prestructured questionnaire was used to collect the data.

Methodology: Collection of data was done retrospectively from the medical records of women who underwent hysterectomy for AUB in the study period from January 2015 to June 2016 in the Department of obstetrics and gynaecology, Karpagam Faculty of Medical Sciences and Research. All the non gravid women who had the symptoms of excessive menstrual blood loss

\section{Original Research Article}

(heavy menstrual bleeding) that interfered with the physical, emotional, social and material quality of life and occurring alone or in combination with other symptoms like irregular menstrual bleeding-variation of $>20$ days in individual cycle lengths over a period of one year, absent menstrual bleeding-no bleeding in a 90-day period, frequent menstrual bleeding-more than four menstrual episodes in a 90-day period, infrequent menstrual bleeding-one or two menstrual episodes in a 90-day period, prolonged menstrual bleeding-menstrual periods exceeding 8 days in duration on a regular basis, shortened menstrual bleeding-bleeding of no longer than 2 days, postmenopausal bleeding-bleeding occurring $>1$ year after the acknowledged menopause, post-coital or intermenstrual bleeding-irregular nonmenstrual bleeding, who underwent planned abdominal hysterectomy and laparoscopy assisted vaginal hysterectomy, were included in the study. Data was entered on proformas which included the clinical features and the demographic factors. Only one prominent diagnosis was documented as the indication for hysterectomy. The clinical, sonological and histopathological findings were noted and analysed so as to identify the proportion of different causes of AUB in women who had undergone hysterectomy. Causes of AUB were categorized by calculating the percentage according to the standard PALM-COEIN classification updated by FIGO. Convenient sampling was done and all nongravid women of age 35 to 65 were included in our study. Statistical analysis was done by entering the data in Microsoft excel and calculating the percentages.

\section{Results}

Table-1: Age wise distribution of women undergone hysterectomy for AUB (n=214).

\begin{tabular}{|c|c|c|}
\hline Age in years & Number & Percentage \\
\hline $36-40$ & 45 & 21.0 \\
\hline $41-45$ & 52 & 24.3 \\
\hline $46-50$ & 95 & 44.4 \\
\hline $51-55$ & 10 & 4.7 \\
\hline $56-60$ & 8 & 3.7 \\
\hline$>60$ & 4 & 1.9 \\
\hline Total & $\mathbf{2 1 4}$ & $\mathbf{1 0 0}$ \\
\hline
\end{tabular}

Out of the 214 cases studied, majority 95 cases (44.4\%) of AUB belonged to the age group 46 to 50 years and about $24.3 \%$ were between 41 to 45 years.

Table-2: Parity of patients undergone hysterectomy for AUB (n=214).

\begin{tabular}{|c|c|c|}
\hline Parity & Number & Percentage \\
\hline Para 1 & 16 & 7.5 \\
\hline Para 2 & 148 & 69.2 \\
\hline Para 3 and above & 45 & 21 \\
\hline Nulliparous & 5 & 2.3 \\
\hline Total & $\mathbf{2 1 4}$ & $\mathbf{1 0 0}$ \\
\hline
\end{tabular}


Most of the cases were multiparous in which $69.2 \%$ belonged to para 2 and $21 \%$ had a parity of 3 and above [Table 2].

Table-3: Classification based on AUB Symptomatology(n=214).

\begin{tabular}{|c|c|c|}
\hline Symptom & Number & Percentage \\
\hline Heavy menstrual bleeding & 52 & 24.3 \\
\hline Irregular menstrual bleeding & 40 & 18.7 \\
\hline Absent menstrual bleeding & 0 & 16.8 \\
\hline Frequent menstrual bleeding & 36 & 1.9 \\
\hline Infrequent menstrual bleeding & 4 & 14.0 \\
\hline Prolonged menstrual bleeding & 30 & 16.4 \\
\hline Heavy and prolonged menstrual & 35 & 0 \\
\hline bleeding & 0 & 4.2 \\
\hline Shortened mentrual bleeding & 9 & 3.7 \\
\hline Postmenopausal bleeding & 8 & $\mathbf{1 0 0}$ \\
\hline Irregular nonmenstrual bleeding & $\mathbf{2 1 4}$ & 0 \\
\hline Total & & \\
\hline
\end{tabular}

Heavy menstrual bleeding was the commonest presentation (24.3\%) followed by irregular menstrual bleeding (18.7\%).

Table-4: Distribution according to the Preoperative diagnosis of patients $n=(214)$.

\begin{tabular}{|c|c|c|}
\hline Preoperative diagnosis & Number & Percentage \\
\hline Fibroids & 74 & 34.6 \\
\hline Adenomyosis & 36 & 16.8 \\
\hline Ovulatory disorder & 51 & 23.8 \\
\hline Chronic PID & 11 & 5.1 \\
\hline Endometriosis & 25 & 11.7 \\
\hline Cervical dysplasia & 10 & 4.7 \\
\hline Cervical polyp & 3 & 0.9 \\
\hline Carcinoma cervix & 2 & 0.9 \\
\hline Carcinoma endometrium & 2 & $\mathbf{1 0 0}$ \\
\hline Total & $\mathbf{2 1 4}$ & 1.4 \\
\hline
\end{tabular}

Fibroid (34.6\%) was the commonest preoperative diagnosis followed by ovulatory disorder (23.8\%).Adenomyosis(16.8\%) ranked the third common preoperative diagnosis.

Table-5: PALMCOIEN classification of AUB cases $(n=214)$.

\begin{tabular}{|c|c|c|c|}
\hline & Histopathological diagnosis & Number & Percentage \\
\hline $\mathrm{P}$ & Polyp(AUB-P) & 3 & 1.4 \\
\hline $\mathrm{A}$ & Adenomyosis(AUB-A) & 46 & 38.5 \\
\hline $\mathrm{L}$ & Leiomyoma(AUB-L) & 4.2 \\
\hline $\mathrm{M}$ & $\begin{array}{c}\text { Malignancies And Hyperplasias } \\
\text { (AUB-M) }\end{array}$ & 0 & 0 \\
\hline $\mathrm{C}$ & $\begin{array}{c}\text { Coagulopathy } \\
\text { (AUB-C) }\end{array}$ & 47 & 22.0 \\
\hline $\mathrm{O}$ & Ovulatory Disorder(AUB-O) & 0 & 0 \\
\hline $\mathrm{I}$ & Iatrogenic(AUB-I) & 27 & 12.6 \\
\hline $\mathrm{E}$ & $\begin{array}{c}\text { Endometrial } \\
\text { (AUB-E) }\end{array}$ & 0 & 0 \\
\hline $\mathrm{N}$ & Not Classified(AUB-N) & 214 & 100 \\
\hline
\end{tabular}


AUB-L contributed $38.3 \%$ followed by AUB-O which constituted 22\% and AUB-A was the third commonest $21.5 \%$ among the cases of AUB.

Table-6: Distribution of patients according to the age group and PALMCOEIN classification.

\begin{tabular}{|c|c|c|c|c|c|c|c|}
\hline Age group & $36-40$ & $41-45$ & $46-50$ & $51-55$ & $56-60$ & $>60$ & Total \\
\hline Polyp (AUB-P) & & $\begin{array}{c}2 \\
(66.7 \%)\end{array}$ & $\begin{array}{c}1 \\
(33.3 \%)\end{array}$ & & & & 3 \\
\hline $\begin{array}{l}\text { Adenomyosis } \\
\text { (AUB-A) }\end{array}$ & $\begin{array}{c}8 \\
(17.4 \%)\end{array}$ & $\begin{array}{c}15 \\
(32.6 \%)\end{array}$ & $\begin{array}{c}18 \\
(39.1 \%)\end{array}$ & $\begin{array}{c}5 \\
(10.9 \%)\end{array}$ & & & 46 \\
\hline $\begin{array}{l}\text { Leiomyoma } \\
\text { (AUB-L) }\end{array}$ & $\begin{array}{c}20 \\
(24.4 \%)\end{array}$ & $\begin{array}{c}31 \\
(37.8 \%)\end{array}$ & $\begin{array}{c}25 \\
(30.5 \%)\end{array}$ & $\begin{array}{c}6 \\
(7.3 \%)\end{array}$ & & & 82 \\
\hline $\begin{array}{c}\text { Malignancies Hyperplasia } \\
\text { (AUB-M) }\end{array}$ & & & $\begin{array}{c}2 \\
(22.2 \%)\end{array}$ & $\begin{array}{c}1 \\
(11.1 \%)\end{array}$ & $\begin{array}{c}2 \\
(22.2 \%)\end{array}$ & $\begin{array}{c}4 \\
(44.4 \%)\end{array}$ & 9 \\
\hline Coagulopathy(AUB-C) & 0 & 0 & 0 & 0 & 0 & 0 & 0 \\
\hline $\begin{array}{l}\text { Ovulatory Disorder } \\
\text { (AUB-O) }\end{array}$ & $\begin{array}{c}2 \\
(4.3 \%)\end{array}$ & $\begin{array}{c}20 \\
(42.6 \%)\end{array}$ & $\begin{array}{c}25 \\
(53.2 \%)\end{array}$ & & & & 47 \\
\hline $\begin{array}{c}\text { Iatrogenic } \\
\text { (AUB-I) }\end{array}$ & 0 & 0 & 0 & 0 & 0 & 0 & 0 \\
\hline Endometrial(AUB-E) & & $\begin{array}{c}4 \\
(14.8 \%)\end{array}$ & $\begin{array}{c}18 \\
(66.7 \%)\end{array}$ & $\begin{array}{c}5 \\
(18.5 \%)\end{array}$ & & & 27 \\
\hline $\begin{array}{l}\text { Not Classified } \\
(\text { AUB-N) }\end{array}$ & 0 & 0 & 0 & 0 & 0 & 0 & 0 \\
\hline Total & 30 & 72 & 89 & 17 & 2 & 4 & 214 \\
\hline
\end{tabular}

Out of the 3 cases of AUB-P, 2 cases were in the age group 41 to 45 years. About $39.1 \%$ of AUB-A belonged to 46 to 50 years. Of the total 82 cases of AUB-L, the commonest cause of AUB, 37.8\% were of the age group 41 to 45 years and $30.5 \%$ were of 46 to 50 years. Four cases of AUB-M were above 60 years of the total 9 cases of AUB-M.AUB-O was almost equally distributed between 41 to 45 years and 46 to 50 years age group. There were no cases with coagulopathy observed in the study.

\section{Discussion}

Hysterectomy is the surgical procedure which involves the total removal of the uterus with or without the fallopian tubes and ovaries. It gives definitive cure to many uterine and adnexal diseases like fibroids, DUB, adenomyosis, endometriosis, pelvic inflammatory disease, pelvic organ prolapse and malignancy. In many countries, now the focus is mainly on minimally invasive conservative management options for benign gynaecological diseases such as endometrial ablation, thermal balloon therapy, uterine artery embolization or levonorgestrel releasing intrauterine system and also on minimally invasive surgeries like laparoscopic hysterectomy, or robotic surgery. But in a country like India, especially in rural areas the resources are very much limited for the above mentioned expensive procedures and also women usually present very late to the health care facility and opt for a permanent treatment to their disease, at the cheapest rates available.

We planned this study due to the effect of the new terminologies, definitions and classification put forth by the FIGO $[1,2,3]$. The recommended normal limits of menses include 3 parameters: frequency, regularity and

Obsgyne Review: Journal of Obstetrics and Gynecology duration of menstrual blood flow. Based on this, the normal menstrual limits will include a frequency of once in every 24-35 days, a variation of $<20$ days in cycle to cycle variation over 12 months, and a duration of menstrual flow between 4.5 to 8 days [3]. Many obscure, poorly defined and extensively used terms such as menorrhagia, polymenorrhea and dysfunctional uterine bleeding have been discarded. Menorrhagia has been replaced by the term heavy menstrual bleeding [3] and polymenorrhea has been replaced by frequent menstrual bleeding [3]. The disorders previously named as dysfunctional uterine bleeding (DUB) has been replaced by coagulopathy / ovulatory disorders / endometrial dysfunction in the PALM-COEIN classification [1]. FIGO has put forth this PALMCOIEN classification for AUB in women to facilitate investigators to study homogenous populations of patients with AUB and to make it easy to compare studies performed by different investigators or research by avoiding the confusing terminologies used before.

About 95 cases $(44.4 \%)$ in our study were of the age group 46 to 50 years [Table1] and $24.3 \%$ cases were of 
Original Research Article

the age group 41 to 45 years which is similar to the study by Mohammad et al[7]. Only about $1.9 \%$ of AUB cases were above 60 years which clearly shows that AUB is a very common symptom in late reproductive age and perimenopausal women rather than postmenopausal. Adenomyosis was most commonly seen in the 46-50 age group followed by 41-45 years and similarly leiomyomas were also common in the $46-50$ age group. [Table 2] $69.2 \%$ of AUB patients in our study were para 2 and $21 \%$ were para 3 or more which is comparable to the study by Mohammed et al[7] who found $65.9 \%$ AUB in para2. Arnold et al has also reported that $38 \%$ were para 2 and $38.5 \%$ were para 3 . Only $2.3 \%$ of AUB patients were nulliparous and $7.5 \%$ cases were para 1 which are comparable with Arnold et al. Hence AUB is a symptom more common among multiparous than in women with parity 1 or 0 .

HMB, the commonest clinical presentation was observed in $24.3 \%$ of the cases and is similar to that of Rizvi et al [4] who found HMB to be more common than irregular menstrual bleeding while Arnold et al[5] had HMB in $43.7 \%$ of cases. Shergill SK found that abnormal menstrual flow was the commonest symptom seen in $66 \%$ cases undergoing hysterectomy. Irregular menstrual bleeding was the presenting symptom in 40 cases $(18.7 \%)$ and the results are comparable to Arnold et al[5]. $14 \%$ patients had prolonged menstrual bleeding while $16.8 \%$ of patients had frequent menstrual bleeding [Table $3]$. AUB-O, the second most common AUB in our study was the third commonest according to Arnold et al [5] and if superimposed on regular cyclic menstruation (24 to 35 days), is usually associated with structural causes [PALM] or sometimes by functional cause [AUB-O] [6].

Leiomyoma was the [Table 4] most common structural abnormality seen $(38.3 \%)$, followed closely by ovulatory disorders (22\%) and adenomyosis (21.5\%), the third commonest histopathological finding and these results are comparable with the study by mohammad et al[7] and Jaleel et al[8]. Sobande AA [9] also found that fibroid was the most common pathology seen in $25.8 \%$ of hysterectomy specimens followed by Adenomyosis (22.7\%). Clarke A [10] has reported the commonest indication to be DUB (58\%), followed by fibroids (23.2\%) and Arnold et al has reported AUB-A is the commonest $(53.4 \%)$.

Literature states that $70 \%$ of adenomyosis patients have AUB symptoms and there is a strong association between the two. In our study [Table 5], $12.6 \%$ of the cases had benign endometrial hyperplasia while Doraiswami et al [11] found $6.1 \%$ of hyperplasia causing AUB. Doraiswami et al[11] found $11.2 \%$ of benign polyps while we obtained $1.4 \%$ benign polyps [Table 5]. AUB in $39 \%$ of premenopausal women and $21-28 \%$ of postmenopausal women are due to polyps as per the literature. Out of the 214 cases, $4.2 \%$ accounted for overall malignancies [Table 6] while malignant tumours comprised only $0.72 \%$ of cases in the study by Rather et al[12] and $15 \%$ of cases in the study by Arnold et al.

\section{Conclusion}

Though numerous medical treatment and conservative surgeries have emerged hysterectomy is the definitive treatment modality for AUB in the developing and the affluent countries. This study does not exclude from the flails of other single hospital-based studies.

However this study gives a basic information and statistics to follow the trend of the hysterectomy and the corresponding histopathological findings in the studied population in a rural based tertiary care centre in south India.

We have classified the specimens according to PALMCOEIN and found out the percentages of each causes of AUB.

More studies must be conducted for finding out the causes for the increased prevalence of leiomyoma in our region. And also confusion regarding the terminology, definitions, and classification of AUB has been put aside by the new standardized terminology, definitions and PALM-COEIN classification for AUB formulated by FIGO and our study will be useful in providing data for comparative and epidemiological studies in different populations based on this standard PALMCOEIN classification.

\section{Funding: Nil, Conflict of interest: Nil Permission from IRB: Yes}

\section{References}

1. Munro MG, Critchley HO, Broder MS, Fraser IS; FIGO Working Group on Menstrual Disorders. FIGO classification system (PALM-COEIN) for causes of abnormal uterine bleeding in nongravid women of reproductive age. Int J Gynaecol Obstet. 2011 Apr; 113 (1): 3-13. doi: 10.1016/j.ijgo.2010.11.011. Epub 2011 Feb 22.

2. Fraser IS, Critchley HO, Broder M, Munro MG. The FIGO recommendations on terminologies and definitions for normal and abnormal uterine bleeding. Semin Reprod Med. 2011 Sep; 29(5): 383-90. doi: 10.1055/ s-00311287662. Epub 2011 Nov 7. 


\section{Original Research Article}

3. Abnormal Uterine Bleeding. [Internet] 2014 May. Available from: http: //www.acog.org/-/media/ Districts/ District- VIII/Abnormal UterineBleeding.pdf

4. Rizvi G, Pandey H, Pant H, Chufal SS, Pant P. Histopathological correlation of adenomyosis and leiomyoma in hysterectomy specimens as the cause of abnormal uterine bleeding in women in different age groups in the Kumaon region: A retroprospective study. $\mathrm{J}$ Midlife Health. 2013 Jan; 4(1):27-30. doi: 10.4103/09767800.109631 .

5. Jonathan arnold,Srivani saravanan,Journal of Evolution of Med and Dent Sci/ eISSN- 2278-4802, pISSN- 22784748/ Vol. 4/ Issue 63/ Aug 06, 2015.

6. Twiss JJ. A new look at abnormal uterine bleeding. Nurse Pract. 2013 Dec 10;38(12):22-30; quiz 31. doi: 10. 1097/01. NPR.0000437574.76024.ef.

7. Mohammed N, Prejisha B. A Study of Correlation of Etiological and Histopathological Findings in Females Undergoing Hysterectomy for Abnormal Uterine Bleeding - in accordance with Palmcoein Classification. Paripex-Indian Journal of Research. 2014 Nov; 3(11): 76-77.

8. Jaleel R, Khan A, Soomro N. Clinicopathological study of abdominal hysterectomies. Pak J Med Sci 2009; 25: $630-4$.
9. Sobande AA, Eskandar M, Archibong EI, Damole IO. Elective hysterectomy: a clinicopathological review from Abha catchment area of Saudi Arabia. West Afr J Med. 2005 Jan-Mar;24(1):31-5.

10. Clarke A, Black N, Rowe P, Mott S, Howle K. Indications for and outcome of total abdominal hysterectomy for benign disease: a prospective cohort study. Br J Obstet Gynaecol. 1995 Aug; 102(8):611-20.

11. Doraiswami S, Johnson $\mathrm{T}$, Rao S, Rajkumar A, Vijayaraghavan J, Panicker VK. Study of endometrial pathology in abnormal uterine bleeding. J Obstet Gynaecol India. 2011 Aug; 61 (4): 426-30. doi: 10. 1007 / s13224-011-0047-2. Epub 2011 Sep 22.

12. Rather GR, Gupta Y, Bardhwaj S. Patterns of Lesions in Hysterectomy Specimens A Prospective Study. JK Science. 2013; 15(2): 63-68.

13. Perveen S, Tayyab S. Clinicopathological review of elective abdominal hysterectomies.J SurPak2008;13:26-9.

14. Bashir R, Parveen Z, Sultana R, Khan B. A two years audit of complications of hysterectomy at Ayub Teaching Hospital Abbottabad. J Ayub Med Coll Abbottabad. 2005 Apr-Jun;17(2):47-9.

\section{How to cite this article?}

Prema N, Sudhakaran R, Divya. B.V, Meerabai V, Maharani. A clinicopathological study of correlation of clinical, sonological and histopathological findings following hysterectomy for abnormal uterine bleeding based on PALM-COEIN Classification. Obs Rev:J obstet Gynecol 2016;2(4):64-69.doi: 10.17511/joog.2016.i04.04. 